University of Wollongong

Research Online

Faculty of Engineering and Information

Faculty of Engineering and Information

Sciences - Papers: Part A

Sciences

$1-1-2009$

\title{
A control strategy for output maximisation of a PMSG-based variable- speed wind turbine
}

M E. Haque

University of Tasmania

K M. Muttaqi

University of Tasmania, kashem@uow.edu.au

M Negnevitsky

University of Tasmania, michael.negnevitsky@utas.edu.au

Follow this and additional works at: https://ro.uow.edu.au/eispapers

Part of the Engineering Commons, and the Science and Technology Studies Commons

Research Online is the open access institutional repository for the University of Wollongong. For further information contact the UOW Library: research-pubs@uow.edu.au 


\title{
A control strategy for output maximisation of a PMSG-based variable-speed wind turbine
}

\begin{abstract}
This paper presents a control strategy for output maximisation of a direct drive permanent magnet synchronous generator (PMSG)-based small-scale variable-speed wind turbine. The control topology uses a single switch three-phase switch-mode rectifi er and the generator torque, and power is controlled by controlling the switch duty cycle of the switch. To extract maximum power from the wind, the torque reference of the PMSG is calculated from generator speed and wind turbine characteristics. From this torque reference, a current reference is calculated using measured DC link voltage and generator speed. The current error is then used to control the duty cycle of the switch-mode rectifier and thereby torque of the generator is regulated through a proportionalintegral regulator. The operational characteristics of the generating system are investigated under varying wind speed through extensive simulations and the results confi rm that the proposed control strategy can maximise the output power under fluctuating wind speeds.
\end{abstract}

\section{Keywords}

turbine, control, strategy, output, maximisation, pmsg, variable, speed, wind

\section{Disciplines}

Engineering | Science and Technology Studies

\section{Publication Details}

Haque, M. E., Muttaqi , K. M. \& Negnevitsky, M. (2009). A control strategy for output maximisation of a PMSG-based variable-speed wind turbine. Australian Journal of Electrical and Electronics Engineering, 5 (3), 263-270. 


\title{
A Control Strategy for Output Maximization of a PMSG Based Variable Speed Wind Turbine
}

\author{
M. E. Haque, Member, IEEE, K. M. Muttaqi, Senior Member, IEEE, and M. Negnevitsky, Senior \\ Member, IEEE
}

\begin{abstract}
This paper presents a control strategy for output maximization of a direct drive permanent magnet synchronous generator (PMSG) based small scale variable speed wind turbine. The control topology uses a single switch three-phase switch-mode rectifier and the generator torque and power is controlled by controlling the switch duty cycle of the switch. To extract maximum power from the wind, the torque reference of the PMSG is calculated from generator speed and wind turbine characteristics. From this torque reference, a current reference is calculated using measured $\mathrm{dc}$ link voltage and generator speed. The current error is then used to control the duty cycle of the switch-mode rectifier and thereby torque of the generator is regulated through a PI regulator. The operational characteristics of the generating system are investigated under varying wind speed through extensive simulations and the results confirm that the proposed control strategy can maximize the output power under fluctuating wind speeds.
\end{abstract}

Index Terms-Output maximization, permanent magnet synchronous generator, switch-mode rectifier, variable speed wind turbine

\section{INTRODUCTION}

$\mathrm{R}$ ecently, there is a first growing interest on wind power generation due to environmental concern and higher oil price. Many countries are affluent in renewable energy resources; however they are located in remote areas where power grid is not available. Local, small scale stand-alone distributed generation system that can utilize these renewable energy resources when grid connection is not feasible. Permanent magnet synchronous generator is suitable for such applications because of their property of self excitation, which allows an operation at a high power factor and high efficiency. Also, the direct drive PMSG is much more promising than other generators because of higher energy density, smaller size, and low losses $[1,2]$.

To extract maximum power from the fluctuating wind, variable speed operation of the wind turbine generator is necessary. This requires a sophisticated control strategy for the generator. Optimum power/torque tracking is popular control strategy as it helps to achieve optimum wind energy utilization [3-7]. Some of these control strategies use wind velocity to obtain the desired shaft speed to vary the generator speed. However, anemometer based control strategy increases cost and reduce the reliability of the overall system. These control strategies are not suitable or too expensive for a small scale wind turbine. Sensorless control method for maximum power point tracking is reported in the literature [5,6]. In [6], the current vector of an interior type PMSG is controlled to optimize the wind turbine operation at various wind speed, which requires six active switches to be controlled. Switchmode rectifier has been investigated for use with automotive alternator with permanent magnet synchronous machines $[8,9]$. The switch-mode rectifier has also been investigated for small scale variable speed wind turbine $[10,11]$.

In this paper, a control strategy for output maximization of a PMSG based small scale wind turbine is developed. The method has the following features:

- The generated ac power from PMSG is converted to dc power though a simple uncontrolled diode bridge rectifier.

- It requires only one active switching device (IGBT), which is used to control the generator torque to extract maximum power.

- It is suitable for small scale wind turbine.

- It is a simple, low cost solution.

The structure of the paper is as follows. The model of the wind turbine-generator system is discussed in section II. The control topology and the wind power generating system are presented in section III. In section IV, simulation results are presented and discussed. Finally conclusions are made in section V.

\section{Modeling of TURBIne-Generator System}

The models of PMSG and wind turbine are presented in the following sub-sections:

\section{A. PMSG Model}

The $d$ - and $q$ - axes voltages of the PMSG can be given by:

$$
\begin{gathered}
v_{d}=-i_{d} R_{s}-\omega \lambda_{q}+p \lambda_{d} \\
v_{q}=-i_{q} R_{s}+\omega \lambda_{d}+p \lambda_{d}
\end{gathered}
$$

where, $\lambda_{d}$ and $\lambda_{q}$ are the $d$ - and $q$ - axes stator flux linkages and are given by the following equations.

$$
\begin{aligned}
& \lambda_{d}=-L_{d} i_{d}+\lambda_{M} \\
& \lambda_{q}=-L_{q} i_{q}
\end{aligned}
$$

The torque equation of an interior permanent magnet synchronous generator is given by [12],

$$
T_{e}=-\frac{3}{2} P\left(\lambda_{d} i_{q}-\lambda_{q} i_{d}\right)=-\frac{3}{2} P\left[\lambda_{M} i_{q}+\left(L_{d}-L_{q}\right) i_{d} i_{q}\right]
$$


For a surface PMSG, which is used in this paper $L_{d}=L_{q}$, therefore, the torque equation becomes:

$$
T_{g}=-\frac{3}{2} P \lambda_{M} i_{q}
$$

The generator torque and rotor speed are related by

$$
T_{g}=T_{m}-J \frac{d \omega_{m}}{d t}-B \omega_{m}
$$

In equations (1-7), $v_{d}, v_{q}, i_{d}, i_{q}, L_{d}$ and $L_{q}$ are the $d$ and $q$ axes stator voltages, currents and inductances respectively, $R_{s}$ is the stator resistance, $\lambda_{M}$ is the amplitude of the flux linkage $(\mathrm{Wb})$ in the stator due to permanent magnet in the rotor, $\omega$ is the electrical angular velocity in $\mathrm{rad} / \mathrm{sec}, \omega_{m}$ is the rotor speed, $B$ is the damping coefficient (Nm.s), $J$ is the moment of inertia $\left(\mathrm{kg} . \mathrm{m}^{2}\right)$, and $P$ is the number of pole pairs. $p$ is the operator $d / d t$. The torque equation given in (5) consists of two terms. The first term represents the excitation torque and the second term is the reluctance torque due to rotor saliency.

\section{B. Wind Turbine Aerodynamic Characteristics}

The amount of power captured by the wind turbine (power delivered by the rotor) is given by [13]:

$$
P_{t}=P_{\text {wind }} \times C_{p}(\lambda, \beta)=\frac{1}{2} \rho A v_{w}^{3} \times C_{p}(\lambda, \beta)
$$

Where, $\rho$ is the air density $\left(\mathrm{kg} / \mathrm{m}^{3}\right), v_{\omega}$ is the wind speed in $\mathrm{m} / \mathrm{s}, A$ is the blades swept area, $C_{p}$ is the turbine rotor power coefficient, which is a function of tips peed ratio $(\lambda)$ and pitch angle $(\beta)$. The coefficient of performance of a wind turbine is influenced by the tip-speed to wind speed ratio (TSR), which is given by:

$$
T S R=\lambda=\frac{\omega_{m} R}{v_{w}}
$$

or, $v_{w}=\frac{\omega_{m} R}{\lambda}$

where, $\omega_{m}=$ rotational speed of turbine rotor in mechanical $\mathrm{rad} / \mathrm{s}$, and $R=$ radius of the turbine. Figure 1 shows a typical $C_{p}$ versus $\lambda$ characteristics of a wind turbine.

By substituting $v_{\omega}$ from equation (10) into equation (8), the turbine power can be written as;

$$
P_{t}=0.5 \rho A C_{p} \times\left(\frac{\omega_{m} R}{\lambda}\right)^{3}
$$

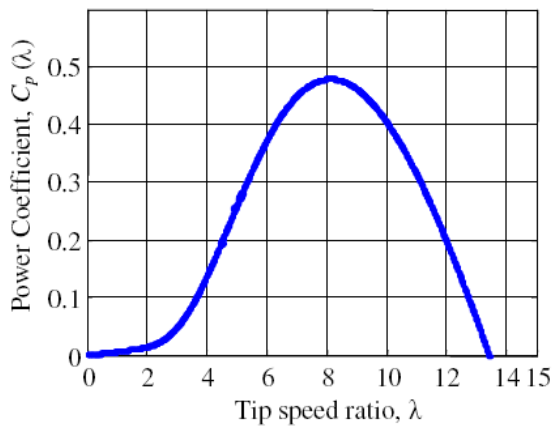

Figure 1. Typical $C_{p}-\lambda$ characteristics.

\section{System CONFIGURATION}

Figure 2 shows the control structure of a PMSG based standalone variable speed wind turbine. However, the single switch three-phase switch-mode rectifier and its control algorithm with output power maximization are investigated in this paper. The standalone system consists of the following:

- Wind turbine

- Permanent magnet synchronous generator, which is directly driven by the gearless wind turbine.

- A single switch three-phase switch-mode rectifier, which is controlled to extract maximum power from the fluctuating wind.

- A PWM voltage source IGBT-inverter.

\section{A. Single Switch Three Phase Switch-mode Rectifier}

The output of a variable speed PMSG is not suitable for use as it varies in amplitude and frequency due to fluctuating wind. A constant DC voltage is required for direct use, storage or conversion to $\mathrm{AC}$ via an inverter. In this paper, a single switch three-phase switch-mode rectifier is used to convert the ac output voltage of the generator to a constant dc voltage before conversion to AC voltage via an inverter.

The single switch three phase switch-mode rectifier consists of a three-phase diode bridge rectifier and a DC to DC converter. The output of the switch-mode rectifier can be controlled by controlling the duty cycle of an active switch (such as IGBT) at any wind speed to extract maximum power from the wind turbine and to supply the loads.

The average output voltage of the rectifier considering the stator resistance and generator leakage inductance is given by:

$$
V_{d}=\frac{3 \sqrt{6}}{\pi} V_{g}-\frac{3}{\pi} \omega L_{s} I_{d}-2 I_{d} R_{s}
$$

where, $\omega=$ frequency, $\mathrm{R}_{\mathrm{s}}=$ stator resistance, $L_{s}=$ leakage inductance, $I_{d}=$ rectifier average output current, $V_{m}=$ maximum line to line voltage at the generator output, $V_{g}=$ RMS phase voltage at the generator output.

The relationship between the terminal voltage of the generator and the DC bus voltage can be derived from the balance of power. From the conservation of energy, the power on the AC side must be equal to the power on the DC side. Assuming that the rectifier operates in continuous conduction, unity power factor is maintained at the generator terminal and losses in power conversion are negligible, the power balance becomes:

$$
3 V_{g} I_{g}=V_{d} I_{d}
$$

From equations (12) and (13), the relationship between the AC generator rms current $\left(I_{g}\right)$ and the DC bus current is given by

$$
I_{d}=\frac{\pi}{\sqrt{6}} I_{g}
$$

The output of the single switch three-phase switch-mode rectifier as shown in figure 2 , is given by

$$
V_{d c}=\frac{1}{1-D} V_{d}
$$




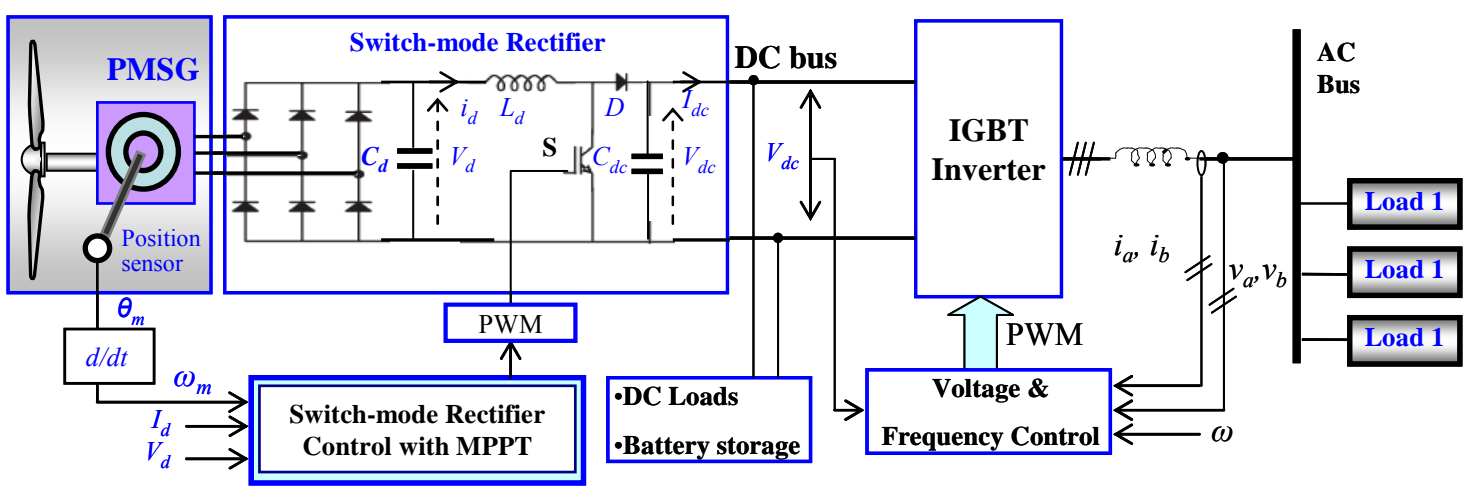

Figure 2. Control Structure of a PMSG based standalone variable speed wind turbine.

Assuming negligible losees in the converter:

$$
\frac{I_{d c}}{I_{d}}=\frac{1}{1-D}
$$

where, the duty ratio, $D=\frac{T_{o n}}{T_{o f f}}, T_{S}=$ period

For the case of boost type switch-mode rectifier, the PMSG should be chosen with terminal voltage at maximum speed to allow for a small voltage boost in the dc-dc converter for all situations.

\section{B. Control Algorithm for Maximum Power Extraction}

It is apparent from equation (11) that the wind turbine can produce maximum power when the turbine operates at maximum $C_{p}$ (i.e. at $C_{p_{-} \text {opt }}$ ). So it is necessary to keep the rotor speed at a optimum value of the tip speed ratio, $\lambda_{\text {opt }}$. If the wind speed varies, the rotor speed should be adjusted to follow the change.

The target optimum power can be written from equation (11) as;

$$
P_{m_{-} o p t}=0.5 \rho A C_{p_{-} o p t}\left(\frac{\omega_{m_{-o p t}} R}{\lambda_{\text {opt }}}\right)^{3}=K_{\text {opt }}\left(\omega_{m_{-} \text {opt }}\right)^{3}
$$

where, $K_{\text {opt }}=0.5 \rho A C_{p_{-} \text {opt }}\left(\frac{R}{\lambda_{\text {opt }}}\right)^{3}$

and $\omega_{m_{-} \text {opt }}=\frac{\lambda_{\text {opt }}}{R} v_{w}=K_{w} v_{w}$

Therefore, the target optimum torque can be given by

$$
T_{m_{-} \text {opt }}=K_{\text {opt }}\left(\omega_{m_{-} \text {opt }}\right)^{2}
$$

The mechanical rotor power generated by turbine as a function of the rotor speed for different wind speed is shown in figure 3. The optimum power is also shown in this figure. The optimum power curve $\left(P_{\text {opt }}\right)$ shows how maximum energy can be captured from the fluctuating wind. The function of the controller is to keep the operating of the turbine on this curve, as the wind velocity varies. It is observed from this figure that there is always a matching rotor speed which produces maximum power for any wind speed. If the controller can properly follow the optimum curve, the wind turbine will produce maximum power at any speed within the allowable range. The optimum torque can be calculated from the optimum power given by equation (20). For the generator speed below the rated maximum speed, the generator follows the equation (20). If the generator speed exceeds the rated maximum speed, the wind turbine energy capture must be limited by applying pitch control or driving the machine to the stall point.

The structure of the proposed control strategy of the switch mode rectifier is shown in figure 4 . The control objective is to control the duty cycle of the switch $\mathrm{S}$ in figure 2, to extract maximum power from the variable speed wind turbine and transfer the power to the load. The control algorithm includes the following steps:

- Measure generator speed, $\omega_{g}$.

- Determine the reference torque (figure 5) using the following equation:

$$
T_{g}^{*}=K_{o p t}\left(\omega_{g}\right)^{2}
$$

- This torque reference is then used to calculate the DC current reference by measuring the rectifier output voltage, $V_{d}$ as given by:

$$
I_{d}^{*}=\left(T_{g}^{*} \times \omega_{g}\right) / V_{d}
$$

- The error between the reference dc current (and measured dc current is used to vary the duty cycle of the switch to regulate the output of the switch-mode rectifier and the generator torque through a PI controller.

The generator torque is controlled in the optimum torque curve in figure 5 according to generator speed. The acceleration or deceleration of the generator is determined by the difference of the turbine torque $T_{m}$ and generator torque $T_{g}$. If the generator speed is less than the optimal speed, the turbine torque is larger than the generator torque and the generator will be accelerated. The generator will be decelerated if the generator speed is higher than the optimal speed. Therefore, the turbine torque and generator torque settle down to the optimum torque point $T_{m_{-} o p t}$ at any wind speed and the wind turbine is operated at the maximum power point. 
For example (considering figure 3), if the PMSG operating at point 'a' and wind speed increases from $v_{w 1}$ to $v_{w 2}$ (point $\mathbf{b}$ ), the additional power and hence torque causes the PMSG to accelerate. The accelerating torque is the difference between the turbine mechanical torque and the torque given by the optimum curve. Finally, the generator will reach the point ' $c$ ' where the accelerating torque is zero. A similar situation occurs when the wind velocity decreases. This is also shown in figure $6(\mathrm{c})$.

In the proposed method, the wind speed is not required to be monitored and therefore, it is a simple output maximization control method without wind speed sensor (anemometer).

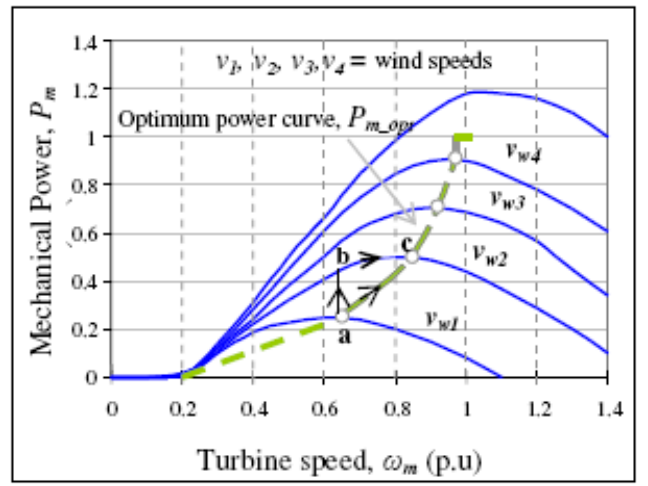

Figure 3. Mechanical power generated by turbine as a function of the rotor speed for different wind speed.

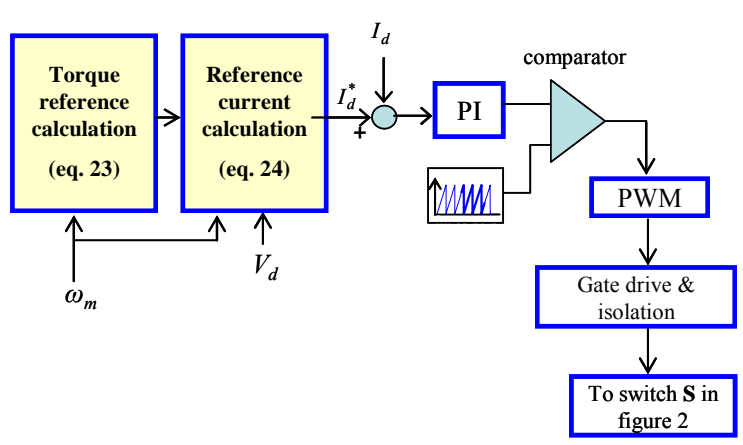

Figure 4. Control strategy of the switch-mode rectifier.

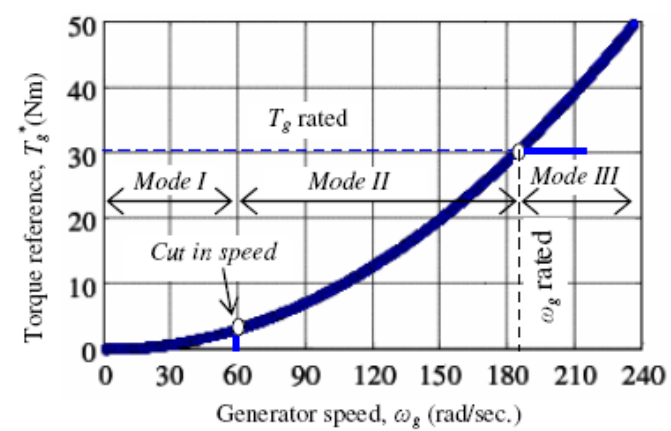

Figure 5. Generator torque reference versus speed.

\section{RESUlTS AND DiscusSiONS}

The model of the PMSG based variable speed wind turbine system of figure 2 is built using Matlab/Simpower dynamic system simulation software. The simulation model is developed based on a Kollmorgen $5.5 \mathrm{~kW}$ industrial permanent magnet synchronous machine. The parameters of the Turbine and PMSG used are given in Table I. The power converter and the control algorithm are also implemented and included in the model. The sampling time used for the simulation is $20 \mu \mathrm{s}$.

Based on the torque regulation of the variable speed wind turbine the operation can be subdivided in three modes as follows:

Mode I (wind speed < Cut in speed): If the wind speed is below the cut in speed (Mode I in figure 5), the power produced by the wind turbine is too low and it is not worth to work with it. So turbine should be shut down.

Mode II (wind speed between cut in speed and rated speed): In this mode, the proposed control strategy is applied and generator follows the torque reference which is given by the equation (21). The blade pitch angle is set to zero to extract maximum power from the wind.

Figure 6 shows the response of the system for a step change of wind speed from $12 \mathrm{~m} / \mathrm{s}$ to $9 \mathrm{~m} / \mathrm{s}$ and to $12 \mathrm{~m} / \mathrm{s}$. It is seen from figure $6(\mathrm{c})$ that the generated torque reference follows the optimum mechanical torque of the turbine quite well. The generator electromagnetic torque also track the reference torque as shown in figure 6(d). Figure 6(e) shows the reference dc current and measured DC current. It is observed that the measured DC current follows the reference DC current and regulate the turbine torque to extract maximum power from the wind turbine. Figure 6(f) and 6(g) show the DC link voltage and dc output power, respectively.

Figure 7 shows optimum torque versus speed as well as generator torque versus speed. Turbine mechanical input power and electrical output powers are shown in figure 8. It is observed that the torque and power follow the optimum curves up to the rated speed.

The simulation results demonstrate that the controller works very well and shows very good dynamic and steady state performance. The control algorithm can be used to extract maximum power from the variable speed wind turbine under fluctuating wind.

Mode III (wind speed > rated speed): If the generator speed exceeds the rated speed, the wind turbine energy capture must be limited by applying pitch control, stall regulation control or dump load. The excess wind energy can also be utilized by using controlled energy storage devices. In this paper, pitch control is used to regulate the turbine speed when the turbine speed is higher than the rated speed. In this operating region, the generator torque can not follow the optimum torque curve; however the available maximum output can be generated as shown in figure 8 . 

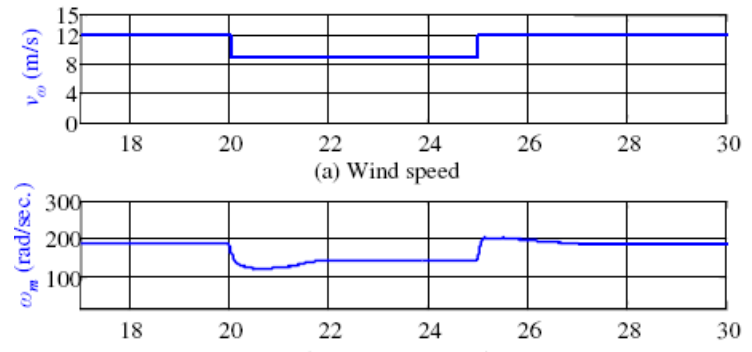

(b) Generator speed

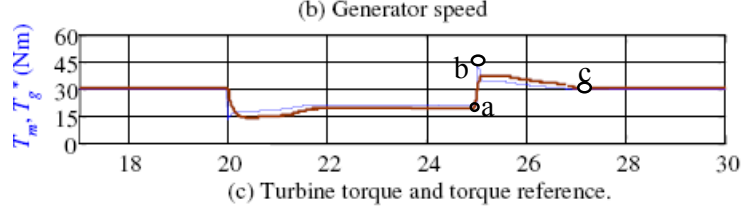

(c) Turbine torque and torque reference.

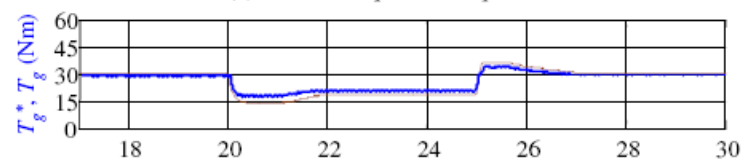

(d) Torque reference and generator electromagnetic torque.

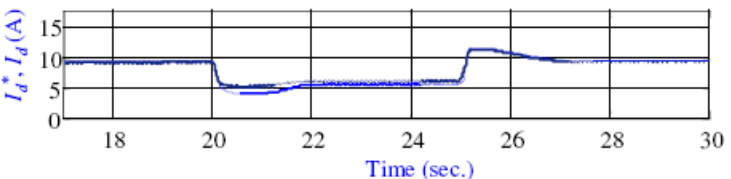

(e) DC current reference and measured dc current.
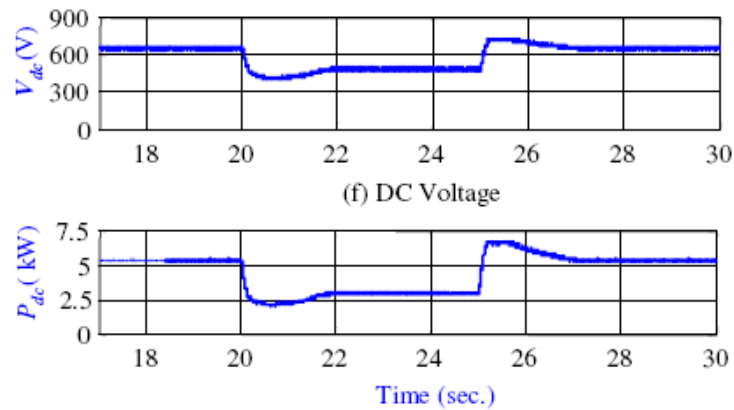

(g) DC power output.

Figure 6. Response of the system for a step change of wind speed from $12 \mathrm{~m} / \mathrm{s}$ to $9 \mathrm{~m} / \mathrm{s}$ to $12 \mathrm{~m} / \mathrm{s}$.

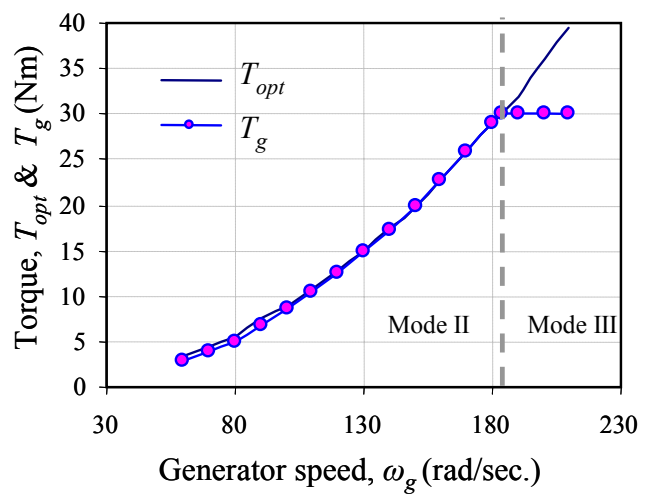

Figure 7. Optimum torque and generator torque.

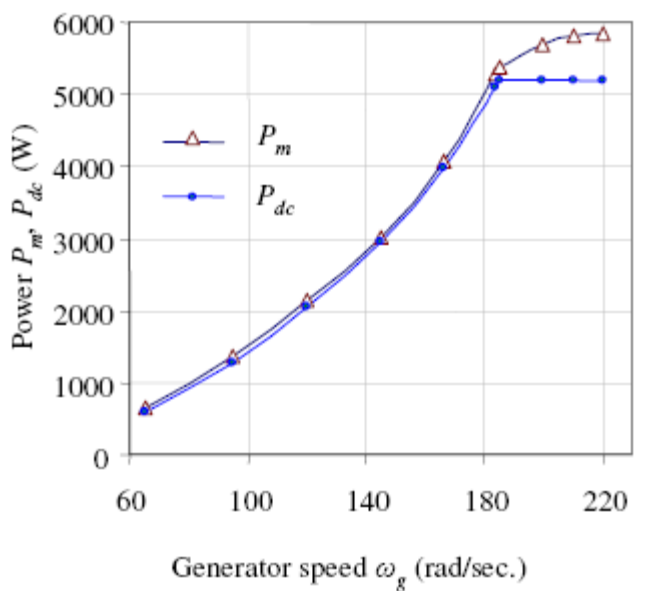

Figure 8. Turbine mechanical input power and Electrical output power.

\section{ACKNOWLEDGMENT}

In this paper, a simple control strategy is proposed to extract maximum power from a PMSG based variable speed wind turbine under fluctuating wind speeds. The modeling of PMSG and wind turbine is presented. The variable speed wind turbine system and the control algorithm are discussed and implemented using MATLAB/Simpower dynamic system simulation software. The simulation results demonstrate that the controller works very well and shows very good dynamic and steady state performance. The controller is capable to maximize output of the variable speed wind turbine under fluctuating wind. The generating system with the proposed maximum power extraction strategy is suitable for a small scale wind turbine installation for remote area power supply.

\section{ACKNOWLEDGMENT}

This work is supported by the Australian research Council ARC) and Hydro Tasmania Linkage Grant, K0015166. The authors greatly acknowledge the support and cooperation of hydro Tasmania personnel in providing data and advice on the operation of remote area power supply system.

Table I: Parameter of the Turbine-Generator system

\begin{tabular}{|l|l|}
\hline \multicolumn{2}{|c|}{ Wind turbine } \\
\hline Density of air & $1.225 \mathrm{Kg} / \mathrm{m}^{3}$ \\
\hline Area swept by blades, $A$ & $1.06 \mathrm{~m}^{2}$ \\
\hline Optimum coefficient, $K_{\text {opt }}$ & $8.885 \times 10^{-4} \mathrm{Nm} /(\mathrm{rad} / \mathrm{s})^{2}$ \\
\hline Base wind speed & $12 \mathrm{~m} / \mathrm{s}$ \\
\hline PMSG & 10 \\
\hline No. of poles & $184 \mathrm{rad} / \mathrm{sec}$ \\
\hline Rated speed & $9 \mathrm{~A}$ \\
\hline Rated current & $0.425 \Omega$ \\
\hline Armature resistance, $\mathrm{R}_{\mathrm{s}}$ & $0.433 \mathrm{~Wb}$ \\
\hline Magnet flux linkage & $30 \mathrm{Nm}$ \\
\hline Rated torque & $5.5 \mathrm{KW}$ \\
\hline Rated power &
\end{tabular}




\section{REFERENCES}

[1] T. F. Chan, L. L. Lai, "Permanenet-magnet machines for distributed generation: a review," in proc. 2007 IEEE power engineering annual meeting, pp. 1-6.

[2] H. Polinder, F. F. A. van der Pijl, G. J. de Vilder, P. J. Tavner, "Comparison of direct-drive and geared generator concepts for wind turbines," IEEE Trans. on energy conversion, vol . 21, no. 3, pp. 725733, Sept. 2006.

[3] A. M. De Broe, S. Drouilhet, and V. Gevorgian, "A peak power tracker for small wind turbines in battery charging applications," IEEE Trans. Energy Convers., vol. 14, no. 4, pp. 1630-1635, Dec. 1999.

[4] R. Datta and V. T. Ranganathan, "A method of tracking the peak powe points for a variable speed wind energy conversion system," IEEE Trans. Energy Convers., vol. 18, no 1, pp. 163-168, Mar. 1999.

[5] K. Tan and S. Islam, "Optimal control strategies in energy conversion of PMSG wind turbine system without mechanical sensors," IEEE Trans. Energy Convers., vol. 19, no. 2, pp. 392-399, Jun. 2004.

[6] M. Chinchilla, S. Arnaltes, and J. C. Burgos, "Control of PermanentMagnet Generators Applied to Variable-Speed Wind-Energy Systems Connected to the Grid” IEEE Trans. on Energy Conver., vol 21, no. 1, March 2006.

[7] D.J. Perreault and V. Caliskan, "Automotive Power Generation and Control”, IEEE Transactions on Power Electronics, Vol. 19, no. 3, pp. 618-630, May 2004.

[8] W.L. Soong and N. Ertugrul, "Inverterless high-power interio permanent-magnet automotive alternator", IEEE Transactions on Industry Applications. Vol.40, no.4, pp.1083-1091, July 2004.

[9] D. M. Whaley, W. L. Soong, N. Ertugrul, "Investigation of switchedmode rectifier for control of small-scale wind turbines", in proc. IEEE Industry applications society annual meeting, pp. 2849-2856, 2005

[10] E. Muljadi, S. Drouilhet, R. Holz, V. Gevorgian, „Analysis of permanent magnet generator for wind power battery charging", in proc. IEEE 1996 Industry applications society annual meeting, pp. 541-548.

[11] P.C Krause, O. Wasynczuk and S. D. Sudhoff, "Analysis of electrical machinery and drive system", IEEE Press, 2002.

[12] G. M. Masters, "Renewable and efficient electric power systems", John Wiley and Sons, 2004.

\section{BIOGRAPHIES}

Md. Enamul Haque (IEEE Student M'97, M'2003) was born in Bangladesh in 1970. He graduated in electrical and electronic engineering from Bangladesh Institute of Technology (BIT), Rajshahi, Bangladesh, in 1995. He received the M.Engg. degree in electrical engineering from University Technology

Malaysia in 1998, and Ph.D. degree in electrical engineering from The University of New South Wales, Sydney, Australia, in 2002. He has worked as an Assistant Professor for King Saud University, Saudi Arabia and United Arab Emirates University for four years. Dr. Haque is currently working as a Research Fellow in the school of Engineering of University of Tasmania, Australia. His research interests include power electronics and DSP based variable speed machine drives, Renewable power generation and associated controls, Wind/Solar remote area power supply system, power quality and $\mathrm{EMC} / \mathrm{EMI}$ issues.

K. M. Muttaqi received the Ph.D. degree from Multimedia University, Malaysia, in 2001. Currently, he is a Senior Lecturer at the School of Engineering and Deputy Director of the Centre for Renewable Energy and Power Systems at the University of Tasmania, Australia. He was associated with the Queensland University of Technology, Australia as a Postdoctoral Research Fellow from 2000 to 2002. Previously, he also worked for Multimedia University as a Lecturer for three years. His special fields of interests include distributed generation, renewable energy, distribution system automation, power system planning, hydroelectric turbine, wind turbine and artificial intelligence.

Michael Negnevitsky (IEEE M'95-SM'07) received the B.S.E.E. (Hons.) and Ph.D. degrees from the Byelorussian University of Technology, Minsk, Belarus, in 1978 and 1983, respectively. Currently, he is Chair Professor in Power Engineering and Computational Intelligence and Director of the Centre for Renewable Energy and Power Systems at the University of Tasmania, Hobart, Australia. From 1984 to 1991, he was a Senior Research Fellow and Senior Lecturer in the Department of Electrical Engineering, Byelorussian University of Technology. After arriving in Australia, he was with Monash University, Melbourne, Australia. His interests are power system analysis, power quality, and intelligent systems applications in power systems. Dr. Negnevitsky is a Chartered Professional Engineer, Fellow of the Institution of Engineers Australia, and a Member of CIGRE AP36 (Electromagnetic Compatibility), Australian Technical Committee. 